e tapeworm in its embryo stage can so lethal to its temporary host. the mortality in fact due to the peworm or to some other cause? H. M. R., Ituna.

Answer: The watery blisters are obably cysts of the dog tapeworm ysticercus pisiformis). These blisrs or white shiny bladers which e found among the intestines or hbedded in the liver, are the larvae the tapeworm. Rabbits may pick the eggs of the tapeworm, on getation which has been contamated by the feces of dogs or coyotes fected with the tapeworms. The gs hatch into tiny larvae in the gestive tract of the rabbit. The ny larvae then make their way rough the walls of the intestine ad remain in the resting state which recognized as the "blister". To complete the life cycle of the tapeworm the raw flesh of the rabbit containing the cysts must be eaten by a member of the dog family. The larvae then develop into adult tapeworms in the intestine of the dog, eggs are produced and the cycle begins again. In contrast to the intermediate host the terminal host (e.g. dog, coyote) will likely become thin and unthrifty. Treatment can be given to dogs to rid them of these parasites.

Although it is commonly believed that the "blisters" in rabbits are responsible for "crash" declines in rabbit populations, this parasite has little or no effect on their mortality. Other diseases or parasites may affect rabbits, however. Tularemia, Rocky Mountain Spotted Fever, tickinduced anemia, "shock disease", may contribute to an increased mortality rate in rabbit populations. - T.A.H.

\title{
S.N.H.S. CHRISTMAS CARDS
}

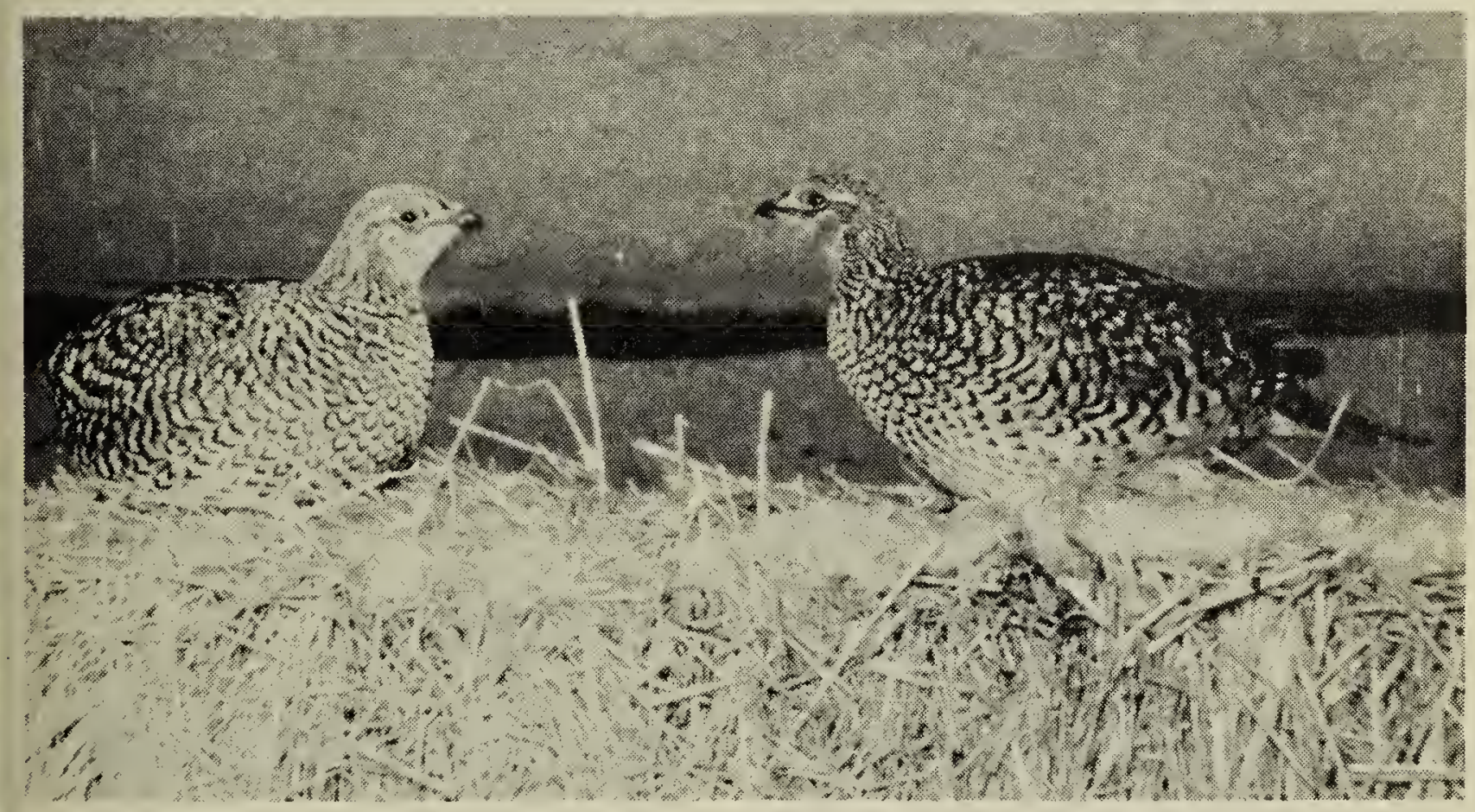

Photo by Doug Gilroy

A coloured reproduction of this dachrome photo of Sharp-tailed rouse, by Doug Gilroy, is being ed this year for S.N.H.S. Christmas rds. The card will be about 4 " $\mathrm{x} 5$ " rd of the folder type. Price: $\$ 1.25$ er dozen.

We expect the cards to be availle in time for the Annual Meeting.
They may be obtained from the following persons:

P. Pawluck, 163 Peaker Avenue, Yorkton, Sask.

Mrs. John Gerrard, 809 Colony Street, Saskatoon, Sask.

Mrs. John Hubbard, Grenfell, Sask.

Frank Burrill, Indian Head, Sask.

Margaret Belcher, Secretary, Blue Jay, Regina College, Regina; Sask. 